\title{
Weerbaar of wendbaar zijn? Strategische opties in de voorbereiding op de drie decentralisaties ${ }^{*}$
}

\author{
Martijn van der Steen \& Mark van Twist ${ }^{*}$
}

\section{Inleiding: een operatie zonder precedent}

Meer maatwerk, zelfredzaamheid en betrokkenheid van burgers, minder verschillende hulpverleners rond één huishouden, het voorkomen van escalatie van problematiek én meer voor minder. Dat zijn ambities voor de decentralisaties in het sociale domein die op dit moment in voorbereiding zijn. Het gaat om een breed domein: van uitkeringen, psychische hulpverlening, thuiszorg, uithuisplaatsing en pleegzorg, re-integratie en beschut werken tot vrijwilligerswerk en activering. Bovendien gaat het naast een technische en administratieve overdracht ook om een verplaatsing van taken in het hart van de huidige verzorgingsstaat en taken die diep ingrijpen in het leven van burgers. Taken krijgen straks invulling vanuit het lokale bestuur, met beleidsvrijheid en politieke ruimte voor gemeenten. Dat heeft gevolgen voor de mensen die van de voorzieningen gebruikmaken en voor de gemeenten zelf.

Elk van de decentralisaties op zich is een majeure operatie, maar opgeteld kent de operatie in de recente geschiedenis van het Nederlandse openbaar bestuur haar gelijke niet. Deze decentralisatie is anders dan de voorgaande, bijvoorbeeld in de financiële omvang en risico's. Het gaat daarnaast om een ingrijpende rolverandering van het lokaal bestuur. Niet alleen de uitvoering van taken overdragen, maar met als achterliggend idee dat de taken voortaan ingebed in maatschappelijke netwerken worden uitgevoerd. Tegen aanmerkelijk minder kosten, een bezuiniging die als ondernemersrisico bij individuele gemeenten ligt. Doen gemeenten het beter dan de ingeboekte bezuiniging, dan houden ze over; doen ze het minder, dan leveren ze zelf in. En als het financieel echt uit de hand loopt, dan is vooralsnog onzeker wat er gebeurt.

Alle gemeenten, ministeries, zorgverleners, de politiek en allerlei belangenorganisaties voeren een debat over hoe de decentralisaties straks invulling krijgen. Zo is er discussie over randvoorwaarden (wat zijn de kaders?), is het pakket in beweging (wat komt er over?), en is er debat over de verdeling van verantwoordelijkheden (wie gaat er straks over?). In deze bijdrage richten we ons op de vraag

* Dit artikel is gebaseerd op het essay Omgaan met het onbekende. Een reflectie op de voorbereiding op de drie decentralisaties (NSOB, 2013). Dat essay is tot stand gekomen als onderdeel van het Meerjarig Kennisprogramma 'Intelligent Bestuur voor een Veerkrachtige Samenleving', waarin de ministeries van BZK, EL\&I en OCW participeren. Naast de beide auteurs van dit artikel hebben ook mr. drs. J.R. de Hoog en A.R. Wendt MSc bijgedragen aan de tekst van dat essay.

** $\quad$ M. van der Steen is co-decaan en adjunct-directeur van de Nederlandse School voor Openbaar Bestuur in Den Haag. E-mail: steen@nsob.nl. Prof. dr. Mark van Twist is decaan en bestuurder van de Nederlandse School voor Openbaar Bestuur en hoogleraar bestuurskunde aan de Erasmus Universiteit Rotterdam (EUR). E-mail: twist@nsob.nl. 
hoe gemeenten zich voorbereiden op deze operatie, tegen de achtergrond van de onzekerheid over wat die operatie behelst. Gemeenten bereiden zich voor op het onbekende, omdat wat overkomt en hoe dat gebeurt, en onder welke condities, onzeker is. Daarnaast is hoe het straks zal werken ook onduidelijk: er is geen ervaring in de nieuwe werkvorm, bijvoorbeeld met de werkelijke bijdrage van eigen kracht en maatschappelijke zelforganisatie, en dus is het moeilijk om daar rekening mee te houden. De gemeenten bereiden zich met grote inzet voor, maar waarop eigenlijk?

In deze beschouwing reflecteren we op de voorbereiding op het onbekende die gemeenten op dit moment in de praktijk doorvoeren. Op basis van literatuur over complexe adaptieve systemen en veerkracht (Perrow, 1984; Sieber, 1981; McMillan, 2004; Abcouwer \& Parson, 2010) schetsen we vier strategieën van voorbereiding op een onbekende toekomst. In een eerdere en meer uitgebreide publicatie (Van der Steen e.a., 2013) hebben we deze strategieën ook empirisch getoetst aan de praktijk van vijf gemeenten.

\section{Voorbereiden op het onbekende: gecompliceerd of complex}

In de meeste beleidsstukken wordt gesproken over het verplaatsen van taken van het Rijk naar de gemeente. 'Verplaatsen' is bij nadere beschouwing te eenvoudig gesteld. Allereerst gaat het niet om een eenvoudige beweging van de ene plek naar de andere, maar om een verplaatsing naar 403 plekken: van het Rijk naar elke individuele gemeente. Daarnaast doet die gemeente het niet zelf, maar samen met andere partijen. Tijdens de verplaatsing verdwijnt bovendien een substantieel deel van het budget, hetzelfde moet met minder geld gebeuren. En tijdens de verplaatsing verandert de operatie ook nog eens wezenlijk van karakter, want de expliciete doelstelling van de decentralisaties is niet dat het werk elders maar bovenal anders gebeurt. Er wordt gesproken in het beeld van een verhuizing van taken, alsof de taken getransporteerd worden van de ene naar de andere plek. Maar in feite gaat het om een transformatie van de manier waarop het sociale domein invulling krijgt. Voor al die genoemde veranderingen geldt dat ze heel verschillend kunnen uitpakken. Steeds liggen de opties open en zijn de uitkomsten het gevolg van lokale voorkeuren en het lokale verloop van het interactieproces.

De decentralisaties zijn daarom niet alleen een gecompliceerde opgave waarin regelingen samenkomen. Het is niet ingewikkeld vanwege de veelheid van spelers of de grote omvang van de taken. In de literatuur noemen we dat gecompliceerd, lastig te tellen, moeilijk te overzien, ingewikkeld te ontrafelen. Maar, voor wie genoeg tijd heeft en moeite doet uiteindelijk wel kenbaar. Het is vooral een zaak van goed uitzoeken en orde aanbrengen. Ingewikkeld, lastig, maar met voldoende inspanning en intelligentie wel tot een goed einde te brengen. Daar staat een andere vorm van 'ingewikkeldheid' tegenover, namelijk complexiteit. Dat is niet de overtreffende trap van gecompliceerd, 'nog een beetje moeilijker', maar een ander soort ingewikkeldheid. De decentralisaties vormen een complex geheel, waarin allerlei zaken op elkaar inwerken en de systeemdynamiek de uitkomsten bepaalt. 
Tabel 1. Gecompliceerd of complex

\begin{tabular}{ll}
\hline Gecompliceerd systeem & Complex systeem \\
\hline Kenbaar, hoewel soms met moeite & Onkenbaar \\
Voorspelbaar binnen bandbreedtes & Onvoorspelbaar \\
Afwijking als te verhelpen uitzondering & Afwijking als onvermijdelijke regel \\
Voorbereiden op de voorzienbare vraag, & Voorbereiden op het onbekende, \\
met reservering voor uitzonderingen & het vermogen om in te spelen op \\
& onverwachte ontwikkelingen \\
\hline
\end{tabular}

Regelingen interfereren met elkaar en mensen reageren verschillend op beleidsmaatregelen. Zo ontstaan onvoorspelbare processen, die kunnen betekenen dat nu verwachte kwesties zich amper voordoen, maar ook dat nu nog onverwachte zaken veel aandacht gaan vragen. Een complex systeem, in dit geval de decentralisaties, is onvoorspelbaar: niet omdat we de moeite niet nemen om het te begrijpen, maar omdat het fundamenteel onkenbaar is. De uitwerking is een gevolg van onvoorspelbare interacties tussen gaandeweg lerende partijen. Dat is niet goed te modelleren, het ontwikkelt zich met de tijd. Het enige wat zeker is, is dat de toekomst anders zal lopen dan nu verwacht. Tabel 1 illustreert de verschillen tussen deze beide benaderingswijzen.

\section{De decentralisaties in voorbereiding: voorspelbaar onverwacht}

De decentralisatieoperatie is nu in voorbereiding. Gemeenten en Rijk maken zich klaar voor een aanstaande toekomst, waarin zij op een andere manier dan nu verantwoordelijkheid gaan dragen voor voorzieningen die direct ingrijpen in de levens van mensen. Dat legt druk op de voorziening, het moet goed. Tegelijkertijd is duidelijk dat de operatie moeilijk in één keer goed kan gaan. Niet vanwege onkunde van gemeenten, maar vanwege de inherente complexiteit van de opgave. Hoe goed de gemeenten zich ook voorbereiden, het is bij voorbaat zeker dat dingen anders zullen lopen dan verwacht. De complexiteit zorgt ervoor dat wat zich straks in de praktijk voltrekt, anders is dan onze huidige verwachtingen erover.

Dat betekent dat gemeenten en het Rijk zich moeten voorbereiden op het onbekende: ze weten nog niet wat hen te wachten staat, maar moeten zich daar nu wel op voorbereiden. Dat roept de vraag op wat voorbereiding in de context van het onverwachte betekent. Hoe bereid je je voor op iets wat je niet kent? We zullen dat hier nader verkennen aan de hand van de begrippen 'gecompliceerd' en 'complex'. Voor een deel is de decentralisatieoperatie een gecompliceerde opgave. Er is een set wetten en regels, financieringsmethodieken en allerhande procedurele zaken die bewegen van de ene naar de andere bestuurslaag. Er moeten contracten worden opgesteld en afspraken worden gemaakt, en professionals moeten met elkaar en met ambtenaren in gesprek over hoe ze de zaken gaan regelen. Dat zijn allemaal administratieve en procedurele organisatieopgaven die alleen met goed doordacht procesmanagement en goed procesontwerp kunnen worden volbracht. Wetgeving moet nader worden uitgewerkt en loopt onderweg vertraging op. Deadlines wor- 
den verschoven, over de financiële kaders bestaat onduidelijkheid. Administratieve systemen moeten worden afgestemd en dat blijkt ingewikkeld. Soms zitten ze elkaar ook in de weg en zijn ze tegenstrijdig. Transitiebureaus en gemeenten zijn druk bezig om dit soort kwesties op te lossen.

Tegelijkertijd is een ander deel van de opgave als complex te duiden. Die blijft in veel gemeenten en bij het Rijk onderbelicht (zie Van der Steen e.a., 2013). De gecompliceerde elementen van de overgang zuigen de aandacht op omdat ze concreet en zichtbaar zijn. Het zijn de problemen van vandaag. Tegelijkertijd doen de belangrijkste kwesties zich straks voor daar waar processen met elkaar interacteren, zij elkaar beïnvloeden en er uit de onderlinge wrijving nieuwe ontwikkelingen opkomen (6, P. 2010; Cavana \& Mares, 2004; Haraldsson, 2000). We weten bijvoorbeeld niet wat er gebeurt als professionals met een integrale blik kijken naar cliënten. De zorgvraag kan afnemen omdat problematiek eerder en effectiever wordt opgelost. Maar de vraag kan ook toenemen omdat cliënten 'ontdekken' dat ze meervoudige problematiek hebben. Hetzelfde geldt voor het mobiliseren van eigen kracht. Daarmee is de afgelopen jaren de nodige ervaring opgedaan, maar het is onzeker wat de gevolgen op grote schaal zijn. Net zoals onduidelijk is wat de inzet van professionals is die nodig is om het netwerk te activeren.

Hoe meer gemeenten gehoor geven aan het onderliggende principe van meer open en met het maatschappelijk netwerk organiseren van de taken, hoe meer complex en onvoorspelbaar hun opgave wordt. Niet onvoorzien omdat ze niet goed kijken, maar omdat de uitkomst nog niet zichtbaar en kenbaar is. Pas wanneer de operatie praktijk wordt, is zichtbaar welke dynamiek er uit ontstaat. De enige manier om het te ontdekken is door te beginnen. Wat betekent dit voor de strategische opties als het gaat om de voorbereiding op de decentralisaties?

\section{Strategische opties: weerbaarheid of wendbaarheid}

De literatuur over veerkracht biedt aanknopingspunten voor het denken over voorbereiding te midden van complexiteit (Folke e.a., 2002; Gunderson \& Holling, 2002; Collins \& Porras, 1994; Weick \& Sutcliff, 2007). De literatuur stelt verschillende afwegingen centraal in het denken over het omgaan met opkomende, onvoorzienbare uitdagingen (Abcouwer \& Parson, 2010). Een cruciale afweging is die tussen strategie gebaseerd op weerbaarheid en strategie gebaseerd op wendbaarheid.

Weerbaarheid duidt op het absorberen van schokken, bijvoorbeeld het opbouwen van buffers om schokken op te vangen (Wildavsky, 1984; Walker e.a., 2004). De idee is dat het probleem niet te voorkomen is, maar dat de buffer ruimte biedt om in te teren. Wendbaarheid kiest een ander principe en zet in op het vermogen om zodra een onverwachte gebeurtenis zich aandient daar snel op in te spelen en er omheen te bewegen (De Bruijne, Boin \& Van Eeten, 2010; Huitema e.a., 2010). Dus niet absorberen en interen, maar aanpassen en overnemen. De klap niet opvangen, maar er omheen sturen. Dat kan proactief, door scherp te kijken naar wat er allemaal kan gebeuren. Net op tijd signaleren en bewegen. Maar het kan ook reactief, door de kiemen van gebeurtenissen snel te ontwaren en na de eerste 
signalen snel het repertoire te veranderen. Bij de eerste impact snel reageren. Dat vereist een organisatie die in staat is tot leren en tot snelle (!) verandering, bijna in real time met wat er gebeurt. Dat is een andere organisatievorm dan die van weerbaarheid, die uitgaat van het 'schrap zetten' en de botsing laat gebeuren. Dat gaat niet om beweging, maar om standvastigheid. De organisatie en de mensen moeten ook in de storm op hun post blijven, terugduwen en niet wijken. Als de organisatie onder druk komt te staan, is er geen ruimte voor twijfel, maar zet men in op volharding.

Onderzoek naar de decentralisatieoperatie (Van der Steen e.a., 2013) maakt duidelijk dat aan de kant van de Rijksoverheid vooral wordt ingezet op het vergroten van de weerbaarheid. De ministeries en de transitiebureaus zoeken naar manieren om de denkbare kwesties in kaart te brengen en deze zo veel mogelijk vóór te zijn. Men streeft ernaar om zo veel mogelijk vooraf te repareren, bijvoorbeeld door regelingen op elkaar aan te laten sluiten, procedures te stroomlijnen en met gemeenten contact te voeren over de informatiebehoefte. Daarnaast zet men sterk in op gemeenten die tegen een stootje kunnen door bundeling van krachten door opschaling.

Ook in gemeenten wordt de strategie van weerbaarheid veel toegepast, zo liet ons onderzoek zien. Zij trekken een stevig bouwwerk op dat de turbulente toekomst kan weerstaan. Ingewikkeld is wel dat inzicht en kennis nodig zijn van wat er te gebeuren staat: wat is het raamwerk waarbinnen men moet presteren, wat wordt precies verwacht, om welke volumes gaat het en met welke problematiek heeft men te maken? Gemeenten die kiezen voor weerbaarheid zoeken naar informatie en houden noodgedwongen de opties open. Er ontbreekt informatie en daarom kan men niet verder. Gemeenten als deze hebben het gevoel in tijdnood te raken: ze willen 'door', maar dat kan niet omdat over cruciale elementen nog geen besluit is genomen en geen helderheid bestaat.

Een ander deel van de gemeenten zet vooral in op robuustheid. Ze bereiden zich voor, maar erkennen dat niet duidelijk is hoe het straks loopt. Daarom leggen ze reserves aan, die hen straks reactietijd bieden om op het onverwachte in te spelen. Belangrijk is dat ze die reserves niet werkelijk aanleggen, maar dat ze het vooral doen door te zoeken naar mogelijkheden om voorlopig minder te leveren. Ze stellen hun ambities bij, wat straks de nodige speelruimte biedt. Ze zijn minder ambitieus in het omarmen van de principes van maatschappelijke inzet, eigen kracht en integrale aanpak. Dat moet zich in de praktijk eerst bewijzen. Deze gemeenten laten alles voorlopig bij het oude en nemen zich voor om na de formele start te onderzoeken wat de best passende aanpak is.

Toch zien we ook gemeenten die in hun strategie inzetten op wendbaarheid. Men rekent er hier op dat de zaken anders zullen lopen dan voorzien. De 'reactie' daarop is om alvast in de nieuwe vorm te beginnen en vooruit te lopen op wat er gaat gebeuren. Omdat alleen dan zichtbaar wordt hoe het uitpakt. Deze gemeenten zetten in hun strategie ook sterk in op maatschappelijke veerkracht in de lokale gemeenschap. Om goed in te kunnen spelen op de onverwachte ontwikkelingen investeren deze gemeenten $\mathrm{nu}$ al in verbindingen met andere gemeenten, met burgers en met professionals. Niet om 'massa te maken' en 'buffers aan te leggen', maar om maximaal leervermogen te mobiliseren en te zorgen dat er 
straks snel praktische oplossingen gevonden worden voor de problemen die zich aandienen. Ook hier dus bundeling en alliantievorming, maar met een andere insteek: niet steviger worden, maar wendbaarder zijn. Gemeenten van dit type stellen het onbekende centraal en oefenen al wat om straks met de ontstane situatie om te kunnen gaan. Gemeenten van dit type hebben vooral zorgen over de mate waarin het Rijk de ruimte blijft bieden om op veerkracht te vertrouwen. Men ziet als risico dat het Rijk toch weer gaat inkaderen en dat de speelruimte uiteindelijk te klein wordt om deze strategie te laten werken.

\section{Conclusie en discussie: temmen of meeveren?}

Onze indruk is dat de decentralisaties vooral zijn op te vatten als een complexe opgave. Er is veel gecompliceerd aan, maar de werkelijke uitdaging schuilt in het element van complexiteit. Dat betekent dat complexiteit in de voorbereiding ook het leidende principe zou moeten zijn. Op dit moment is dat niet wat we waarnemen. De voorbereiding op het rijksniveau richt zich op de gecompliceerde delen van de opgave. Voor de complexe delen rust men bewust of onbewust vooral op een strategie van weerbaarheid: buffers vormen en reserves aanleggen. Dat is volgens ons geen optimale strategie. Belangrijker is misschien nog wel dat door de focus op het oplosbare gecompliceerde verwachtingen worden gewekt die in de praktijk onhaalbaar zullen blijken. Exemplarisch is hoe over de overgang wordt gesproken: burgers zullen er geen hinder van ondervinden. Dat is een in de praktijk onhoudbare gedachte. De essentie van een complexe opgave is dat de contouren ervan zich pas manifesteren tijdens het proces. Mensen die hun zorg te laat krijgen, systemen die niet werken of procedures die uit de hand lopen zijn onvermijdelijk. Niet als excessen, maar als dure leermomenten van een complexe opgave. Een verandering zo groot als deze decentralisatieopgave gaat niet zonder incidenten en problemen. De enige reële belofte is om die met alle macht te lijf te gaan - zodra ze zich voordoen. Om de decentralisaties te laten slagen moeten gemeenten investeren in het vermogen wendbaar te zijn en snel van elkaars ervaringen te leren. Omdat het temmen van complexiteit niet lukt, is meeveren de enige passende strategische optie.

\section{Literatuur}

6, P. (2010). When Forethought and Outturn Part. In: H. Margetts, P. 6 \& C.C. Hood (Eds.), Paradoxes of Modernization: Unintended Consequences of Public Policy Reform. Oxford: Oxford University Press, 44-60.

Abcouwer, A.W., \& Parson, B.G. (2010). Duurzame weerbaarheid: de adaptieve cycle of resilience; is nieuwsgierigheid te organiseren. Adaptivecycle.nl, geraadpleegd op 16 januari 2014.

Bruijne, M. de, Boin, A., \& Eeten, M. van (2010). Resilience: Exploring the concept and its meanings. In: L.K. Comfort, A. Boin \& C.C. Demchak, Designing Resilience: Preparing for Extreme Events. Pittsburg: University of Pittsburgh Press, 13-32. 
Cavana, R.Y., \& Mares, E.D. (2004). Integrating critical thinking and systems thinking: from premises to causal loops. System Dynamics Review, 20 (3): 223-235.

Collins, J., \& Porras, I.J. (1994). Built to Last: Successful Habits of Visionary Companies. New York: Harper Business.

Folke, C., Carpenter, S., Elmqvist, T., Gunderson, L.H., Holling, C.S., \& Walker, B. (2002). Resilience and Sustainable Development: Building Adaptive Capacity in a World of Transformation. AMBIO: A Journal of the Human Environment, 31 (5): 437-440.

Gunderson, L.H., \& Holling, C.S. (2002). Panarchy: Understanding Transformation in Human and Natural Systems. Washington: Island Press.

Haraldsson, H.V. (2000). Introduction to Systems and Causal Loop Diagrams. Lumes: Lund University, 1-33.

Huitema, D., Steur, B., Steen, M. van der, \& Zouridis, S. (2010). De veerkracht van de Nederlandse Democratie, Bestuurskunde, 18 (3): 241-262.

McMillan, E. (2004). Complexity, Organizations and Change. Londen: Routledge.

Perrow, C. (1984). Normal accidents. New York: Basic Books.

Sieber, S.D. (1981). Fatal Remedies: The Ironies of Social Intervention. New York: Plenum.

Steen, M. van der, Hoog, J. de, Wendt, A., \& Twist, M. van (2013). Omgaan met het onbekende. Den Haag: Nederlandse School voor Openbaar Bestuur.

Walker, B., Holling, C.S., Carpenter, S.R., \& Kinzig, A. (2004). Resilience, adaptability and transformability in social-ecological systems. Ecology and Society, 9 (2): 1-5.

Weick, K.E., \& Sutcliff, K.M. (2007). Managing the Unexpected: Resilient Performance in an Age of Uncertainty. San Francisco: Jossey-Boss.

Wildavsky, A. (1984). Trial Without Error: Anticipation Versus Resilience as Strategies for Risk Reductions. New South Wales: Center for Independent Studies. 